\title{
STAG2 Gene Mutation
}

National Cancer Institute

\section{Source}

National Cancer Institute. STAG2 Gene Mutation. NCI Thesaurus. Code C153513.

A change in the nucleotide sequence of the STAG2 gene. 